Article

\title{
Perch Positioning Affects both Laying Hen Locomotion and Forces Experienced at the Keel
}

\author{
Christina Rufener ${ }^{1,2, * \mathbb{D}}$, Ana K. Rentsch ${ }^{2,3}$, Ariane Stratmann ${ }^{2}$ and Michael J. Toscano ${ }^{2}$ \\ 1 Center for Animal Welfare, Department of Animal Science, University of California, Davis, CA 95616, USA \\ 2 Center for Proper Housing: Poultry and Rabbits, Animal Welfare Division, University of Bern, \\ 3052 Zollikofen, Switzerland; arentsch@uoguelph.ca (A.K.R.); ariane.stratmann@vetsuisse.unibe.ch (A.S.); \\ michael.toscano@vetsuisse.unibe.ch (M.J.T.) \\ 3 Department of Animal Biosciences, University of Guelph, Guelph, ON N1G 2W1, Canada \\ * Correspondence: cbrufener@ucdavis.edu
}

Received: 27 May 2020; Accepted: 3 July 2020; Published: 18 July 2020

check for

Simple Summary: Keel bone fractures in laying hens can occur due to falls and collisions within the housing system, although other factors such as genetics and nutrition contribute to the high fracture prevalence found in commercial laying hens. In addition, routine behaviors such as dustbathing or locomotion might contribute to the problem due to accumulated forces at the keel. To understand how locomotion affects the risk to sustain a fracture, we trained 20 brown and 20 white laying hens to jump from a platform to a perch installed at different angles, distances, and directions. We found that longer distances and steeper angles - especially during downward transitions-resulted in higher force at the keel and were more difficult for the hens to navigate. Our results show that perch position has an impact on the forces which a keel bone needs to absorb during controlled movements. In addition, perch position affects the hens' ability to move safely from perch to perch, i.e., without falls and collisions. Optimizing perch position could help to create a safer environment for laying hens and might reduce keel bone fractures.

\begin{abstract}
The aim of this study was to assess the effect of perch positioning on laying hens' locomotion and the resulting energy experienced at the keel. Twenty Nick Chick and 20 Brown Nick hens were trained to transition from a platform to a perch in several configurations. Three variables of perch positioning were tested in a $2 \times 2 \times 2$ factorial design: direction (upward vs. downward), angle (flat vs. steep), and distance (50 cm vs. $100 \mathrm{~cm}$ ). All hens were tested for five jumps of each treatment combination at 27-28 weeks of age. As predicted, we found steep angles and long distances to result in higher peak forces and impulse during take-off, flight, and landing; longer latency to jump; a higher likelihood to perform balancing movements; and a longer latency to peck at the provided food reward. The effect of perch positioning on locomotion and force at the keel during downwards jumps and flight was more pronounced in Brown Nick hens than in Nick Chick hens. Although we cannot state how the observed forces at the keel relate to the risk for keel bone fractures, our results indicated that optimizing perch positioning can reduce accumulated forced at the keel and consequent risk for fracture due to unsuccessful transitions.
\end{abstract}

Keywords: perch; position; angle; distance; acceleration; peak force; locomotion

\section{Introduction}

Alternative housing systems for laying hens such as aviaries are becoming more common as consumer demand shifts towards eggs from non-cage systems [1]. Although aviaries provide many benefits to hens, e.g., the ability to perform species-specific behaviors [2,3], it is speculated that the 
height and difficulty maneuvering within the system increase the risk for falls and injuries [4,5]. Falls can result in collisions with other hens or pen furnishings which are assumed to be one of the reasons for the high prevalence of keel bone fractures in laying hens (reviewed in [6]). The risk for falls and collisions likely relates to positioning of furnishings that determine how birds move between them. Characteristics of movements, including direction [7,8], angle [8-10], and distance [11,12], affect whether hens can move successfully between perches.

Although falls and collisions are suspected to result in fractures [13], a single histopathological characterization of keel bone fractures indicated that high energy collisions are unlikely to be the underlying cause for the majority of fractures in laying hens [14]. An alternative pathogenesis to trauma might be accumulated forces during routine behaviors such as roosting or dust bathing (reviewed in [6]). Similarly, stress fractures in humans occur when bone is exposed to repeated stress (fatigue fractures [15]) or due to stress applied to a bone with deficient elastic resistance (insufficiency fractures [16]). Thus, fractures may conceivably result from both high as well as low energy forces applied to the keel necessitating a need for a comprehensive understanding of how collisions as well as controlled movements relate to forces experienced at the keel.

Although there is evidence that increasing perch height is associated with increasing forces acting on the hen itself [17], it is unknown how these forces are experienced at the keel during innocuous routine activities. The aim of the current study was to assess the effect of perch positioning on bird locomotion and the resulting energy experienced by the keel. Multiple perch positions similar to those used in commercial aviary systems were tested for their effect on hen locomotion-related behaviors and physical properties of movement. Peak force and impulse at the keel during take-off, flight, and landing were measured by an accelerometer placed in a fabric vest with the sensor directly on the keel bone, $3 \mathrm{~cm}$ above the caudal tip. We hypothesized that angle, distance, and direction of movement would affect forces experienced at the keel and navigation-related behaviors (e.g., latency to jump and balancing movements).

\section{Animals, Material and Methods}

\subsection{Ethical Approval}

Ethical approval to conduct the study was obtained from the Veterinary Office of the Canton of Bern in Switzerland (approval number BE22/17). The experiment complied with Swiss regulations regarding the treatment of experimental animals.

\subsection{Animals and Housing}

Eighty Nick Chick and 80 Brown Nick (white and brown feather colored, respectively) day-old chicks provided by a commercial hatchery were reared in one pen of a barn alongside 440 other chicks (300 Nick Chick, 300 Brown Nick in total). The rearing pen contained a commercial multi-tier aviary system (NATURA Aufzucht 187, Inauen AG, Appenzell, Switzerland) with two grid and two perch tiers, a floor covered with wood shavings, and an enclosed wintergarden with perches that the pullets had daily access to from six weeks of age. The rearing system provided access to two tiers with round metal perches coated with a $2 \mathrm{~mm}$ layer of plastic (outer diameter: $3.6 \mathrm{~cm}$ ) installed at $43 \mathrm{~cm}$ above the first grid tier and $50 \mathrm{~cm}$ above the second grid tier. The total height of the aviary was $195 \mathrm{~cm}$. Birds moved between grid tiers using platforms that were installed at both aviary sides. In the wintergarden, wooden, rectangular A-frame perches at 54 and $110 \mathrm{~cm}$ height with an angle of $58^{\circ}$ between them were available. Hens were given ad libitum access to a standard pullet diet. Stocking density during rearing was based on the Swiss Animal Welfare Ordinance with 16.4 birds per $\mathrm{m}^{2}$ grid surface.

At 16 weeks of age, hens were transferred to an experimental barn and randomly assigned to eight identical pens ( $\mathrm{n}=20$ birds per pen; four pens with Nick Chick and four pens with Brown Nick hens). Each hen was identified by a unique number on a plastic, flexible leg band (Roxan ID, Selkirk, UK) on 
the left leg and a specific combination of colored leg rings referring to the pen-specific identification number on the right leg.

The eight pens were set up side by side in the middle of an experimental barn. The distance between the building wall and the short side of the pens was approximately $2 \mathrm{~m}$. Each pen included two compartments: a home pen and a test pen (Figure 1). The home pen $(4 \mathrm{~m} \times 2 \mathrm{~m})$ contained a $7.4 \mathrm{~m}^{2}$ littered area, a round feeder (diameter: $50 \mathrm{~cm}$ ), five nipple drinkers, and a nest box (area: $\left.0.6 \mathrm{~m}^{2}\right)$. Two round metal perches $(1.5 \mathrm{~m}, 3.2 \mathrm{~cm}$ diameter) and an elevated metal grid platform (width $\times$ length: $30 \mathrm{~cm} \times 1.5 \mathrm{~m}$ ) were installed at a height of $1.3 \mathrm{~m}$. Perches were arranged on either side and parallel to the platform separated by a distance of $30 \mathrm{~cm}$. Perches and platform were placed at the same height in order to prevent bias developing in the new environment in terms of jumping abilities, i.e., hens being familiar with a certain angle or distance. Hens were discouraged from jumping to these elements directly from the ground by the combination of structure height $(1.3 \mathrm{~m})$ and pen width $(2 \mathrm{~m})$ resulting in a steep angle and long diagonal distance between floor and elevated structures. Instead, a ramp was installed which transitioned to the platform from the floor (length: $1.78 \mathrm{~m}$; angle from the floor: $47^{\circ}$ ) to make the platform and perches accessible. Besides preventing the hens from developing biases regarding specific angles or distances, the arrangement of platform and perches ensured that hens were familiar with all surfaces used in the test procedure. As the elevated elements were accessible via the ramp, hens walked upwards on the ramp until they reached the platform with perches positioned parallel. Most hens also used the ramp to descend from the perches, though some individuals jumped from the perches to the litter directly (personal observations). The platform/perch arrangement simulated the conditions that were tested in the experiment, where hens were required to jump from a platform and land on a perch.

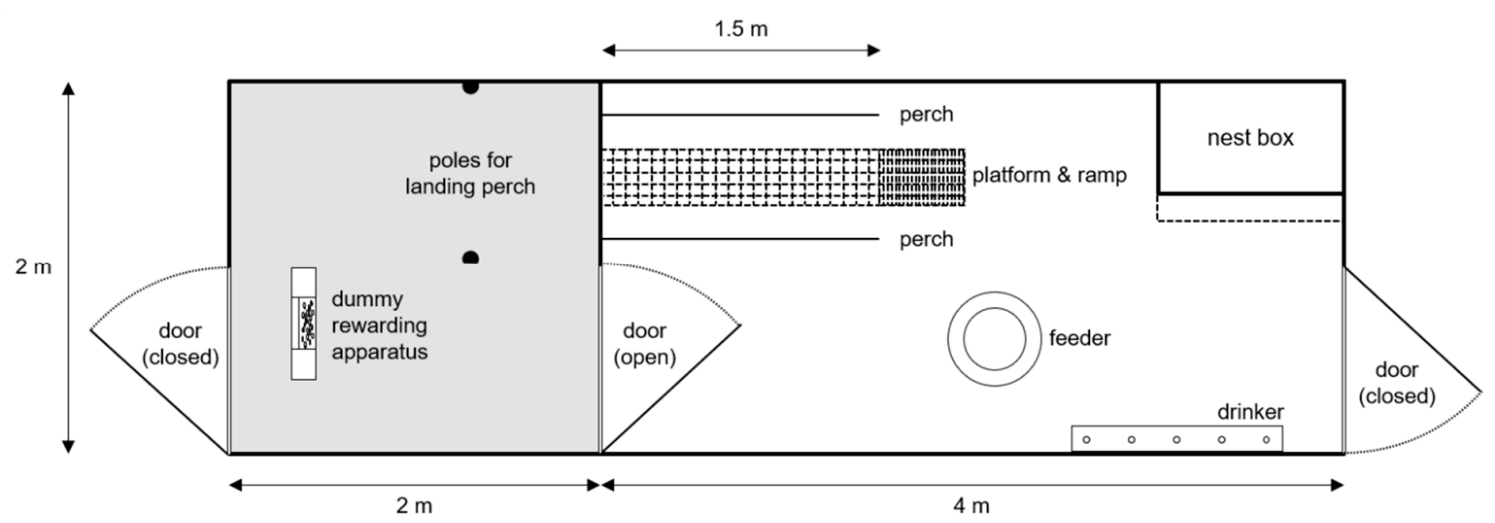

Figure 1. Top view of an experimental pen with test pen (left; gray background) and home pen (right) where hens had access to both pen compartments (i.e., if no training or testing took place). The home pen contained a feeder, nipple drinkers, nest box with landing board, perches, platform, and a ramp leading to the floor. The test pen contained vertical poles which held the landing perch during testing and a dummy rewarding apparatus for habituation.

The test pen (area: $2 \mathrm{~m} \times 2 \mathrm{~m}$ ) contained two vertical poles which held the landing perch during testing. In between training sessions, all testing equipment was removed from the test pen which was then made freely accessible to all hens. The test pen also contained litter to the same depth as the home pen. The grid of the wall and the door separating test pens and home pens was covered with plastic sheets to inhibit visual contact between pens during training and testing.

Light was provided by LED lamps from 04:00 $\mathrm{h}$ with a $10 \mathrm{~min}$ dawn phase to 19:00 $\mathrm{h}$ with a $25 \mathrm{~min}$ dusk phase. Windows were incorporated in the walls of the building, i.e., approximately $2 \mathrm{~m}$ away from the short sides of the pens, and availability of daylight was controlled with curtains which were raised between 05:00 and 18:00 h. Hens were provided feed ad libitum with a standard layer diet (FORS 2051, Burgdorf, Switzerland). Animal care staff always entered the pens through the door of the home pen, whereas the experimenters entered the pens through the door of the test pen. 


\subsection{Rewarding Apparatus}

Hens were trained using a rewarding apparatus that was constructed from a commercial feed trough and covered with a metal plate. Using a switch connected to the device by a $2 \mathrm{~m}$ cable, a flap over the metal plate covered the food reward (wheat grains) but could be opened and closed. The rewarding apparatus was intended to standardize the rewarding process and prevent hens from being distracted by the experimenter. The apparatus used signals (LED lighting and sounds) to communicate the trial's initiation and availability of food. For habituation to the rewarding apparatus, a dummy rewarding apparatus was placed in all eight test pens from the first day of population on (16 weeks of age). The dummy rewarding apparatus was the same size and material as the rewarding apparatus, but the flap covering the reward was constantly open.

\subsection{Habituation to the Test Pen and Selection of Focal Hens}

After a week of habituation to the new environment with both test pen and home pen being freely accessible, hens were gradually introduced to isolation in the test pen over a two-week period. Initially, hens were isolated in groups of two (one week of daily, $10 \mathrm{~min}$ sessions) and then individually (one week of daily, 5 min sessions). Observations of the hens' behavior (e.g., escape attempts or stress calls) were conducted and used to exclude hens which did not habituate to isolation in the test pens. Hens that were excluded from the study were not assessed further. Within the same initial three-week period (one week of habituation and two weeks of isolation), hens were also introduced to the dummy rewarding apparatus containing freely available wheat grains. At 19 weeks of age, the dummy was gradually replaced with the actual test apparatus. Depending on the hens' individual interaction with the test apparatus, 40 Brown Nick and 40 Nick Chick hens were selected as focal hens. A full description of the habituation protocol and hen selection criteria is available in Appendix A.

\subsection{Training}

From 20 weeks of age, selected focal hens (40 Brown Nick, 40 Nick Chick hens) were introduced to the testing apparatus in the test pen (Figure 2). Vertical poles in the test pen held the landing perch and rewarding apparatus. For take-off, a platform identical to the platform in the home pen was used. The landing perch and the rewarding apparatus could be adjusted vertically, whereas the take-off platform could be moved horizontally only. In order to create all test conditions, two take-off platforms of different heights (60 cm above ground for upward jumps and $135 \mathrm{~cm}$ above ground for downward jumps) and variable heights of the landing perch were combined.

Hens were trained individually on five days per week between 8:00 and 12:30 h. The order of pens was stratified to expose hens to training at different times of day. No feed restriction prior to training was applied. Before training started the doors between the test pen and home pen were closed in all pens, thus a hen being trained in the test pen did not have visual contact to hens in the home or adjacent test pens. Within pens, focal hens were picked for training randomly.

Training consisted of stages with each lasting one week in duration. After each week, focal hens not fulfilling inclusion criteria were excluded from further training. Whereas the first two weeks of training served to habituate the hens to the testing apparatus in the test pen, the next four weeks aimed to prepare the hens for the test conditions applied during the testing phase. During the last stage of training, remaining hens were habituated to a vest of flexible fabric (previously used in [18,19]) that allowed full freedom of movement and contained the accelerometer. Vests were custom made with two different sizes and colors (white and brown, respectively) for Nick Chick and Brown Nick hens. The vests allowed the accelerometer to be placed directly at the keel during testing as well as a number on the back for identification. A full training protocol is provided in Appendix B. 


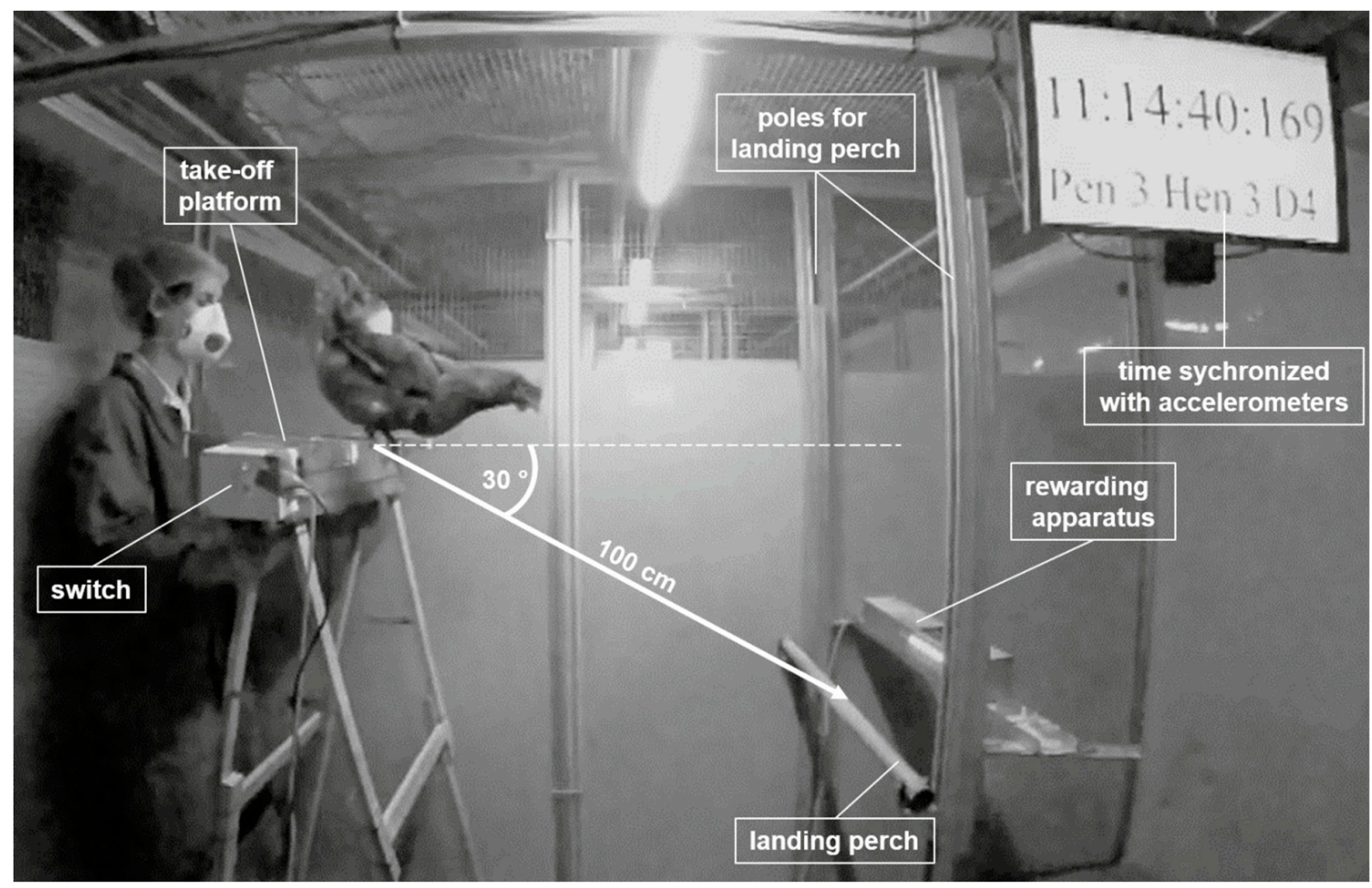

Figure 2. Testing apparatus in the test pen. Landing perch and rewarding apparatus are installed on both sides of the vertical poles. In this example, the take-off platform is placed with $100 \mathrm{~cm}$ diagonal distance to the landing perch with a $30^{\circ}$ angle. The switch to open the flap of the rewarding apparatus is mounted on the take-off platform. The experimenter has her hands placed underneath the take-off platform with a neutral body posture.

\subsection{Experimental Design and Test Conditions}

Twenty Nick Chick and 20 Brown Nick hens (4-7 hens/pen) completed the training protocol successfully and were included in the study. Three factors of perch positioning were tested in a $2 \times 2 \times 2$ factorial design (i.e., 8 treatment combinations or conditions; Figure 3): direction (upward vs. downward), angle (flat: $30^{\circ}$ for upward, $15^{\circ}$ for downward jumps vs. steep: $60^{\circ}$ for upward, $30^{\circ}$ for downward jumps), and diagonal distance $(50 \mathrm{~cm}$ vs. $100 \mathrm{~cm})$. All hens were tested for all conditions. Angles and distances were selected based on existing literature $[7,9,11]$ to include a range of difficulty but unlikely to result in collisions.

Due to the time required for the installation of the testing equipment, half of the pens $(10 \mathrm{Nick}$ Chick and 10 Brown Nick hens) were tested per day. Testing took place on five days per week from 8:00 - 12:00 h over a period of 17 days. Pens and hens within pens were tested in a predefined order, whereas the order of the conditions was counterbalanced between hybrids, individuals, and time of day. As 40 hens were tested for eight conditions each, 320 test sessions were conducted on 16 days (27-30 weeks of age). Per test session, hens were required to jump 3-5 times depending on the motivation to jump, resulting in approximately 1600 jumps for the experiment.

\subsection{Data Collection}

The doors between the test and home pens were closed in all pens during testing. Within the test pen, a video camera was connected to a laptop with a screen displaying a time stamp (described below). Vertical height of the landing perch and rewarding apparatus and horizontal distance of the take-off platform was adjusted for the first hen/condition. The hen was caught and checked for the absence of injuries, wounds, and bumble foot, and palpated to detect the presence or absence of keel bone fractures [20], but no such conditions were found during the testing phase. The accelerometer was 
placed in the hen's vest, the hen placed on the landing perch, the video recording started, and the flap of the rewarding apparatus opened. After five seconds of feeding, the flap of the rewarding apparatus was closed, and the hen returned to the take-off platform with the experimenter's hand remaining on the back of the hen until initiation of the signal. After a successful jump, the hen was allowed to feed for five seconds. The procedure was repeated five times with the first serving to acclimate the hen to the procedure. After the final transition, the accelerometer was removed and the hen returned to the home pen.

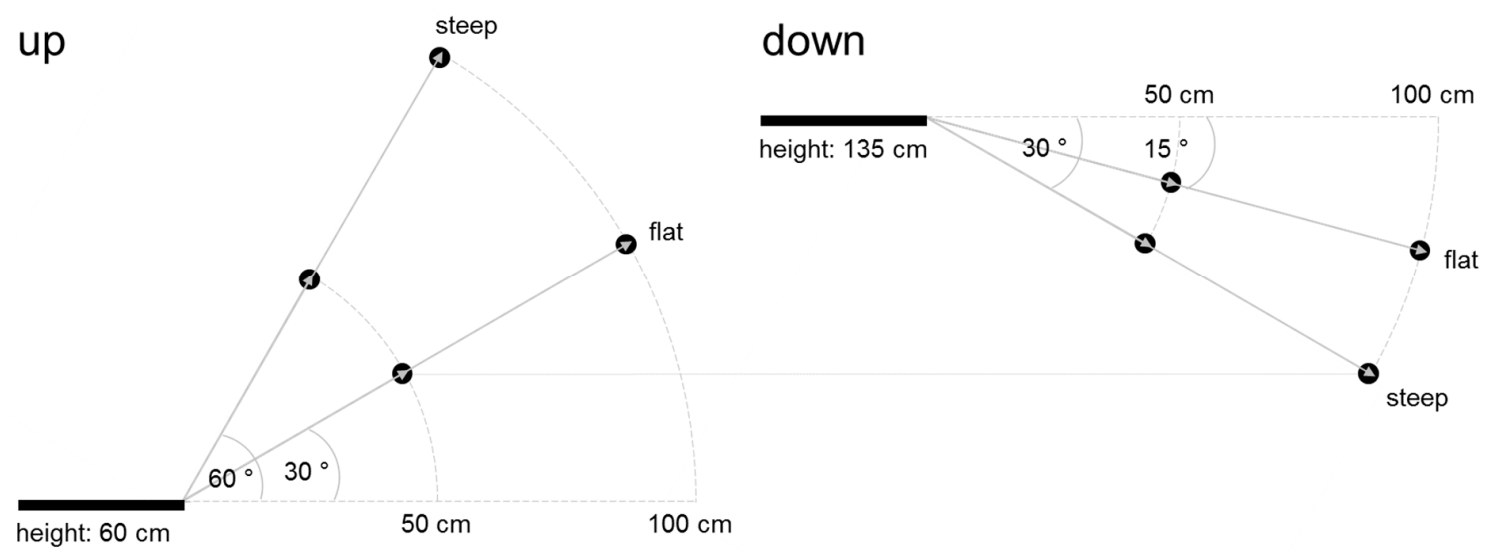

Figure 3. Test conditions based on a $2 \times 2 \times 2$ factorial design combining steep and flat angles, $50 \mathrm{~cm}$ and $100 \mathrm{~cm}$ distance, and upward and downward jumps. The bar represents the take-off platform at different heights for up and down, whereas the dots show the positioning of the landing perch for all treatment combinations. The landing perch for the condition up $/ 50 \mathrm{~cm} / \mathrm{flat}$ was installed at the same height as the landing perch for the condition down $/ 100 \mathrm{~cm} / \mathrm{steep}$.

\subsubsection{Video Recording}

Test sessions were recorded with 240 frames per second (fps) using a high-frequency camera (GoPro HERO5 black, GoPro, Inc., San Mateo CA, USA). The camera was installed at the metal grid wall dividing the test pens. As the camera provided an internal time stamp only which could not be synchronized with the other testing equipment, a screen (EIZO FORIS FG2421; EIZO, Hakusan, Ishikawa, Japan) showing the computer time with a frequency of $120 \mathrm{fps}$ was installed in the test pen during testing.

Using video software enabling movement between single frames (SMPlayer), the duration of the variables described in Table 1 were assessed with a resolution of milliseconds ( $0.000 \mathrm{~s})$ using an adjustment described in Appendix B. For each transition, multiple variables were calculated including latency to jump (time from Signal to Take-off start; Table 1), duration of take-off (time from Take-off start to Take-off end), duration of flight (time from Take-off end to Landing start), duration of landing (time from Landing start to Landing end), and the latency to peck (time from Landing end to First peck). The occurrence of balancing movements after landing (i.e., first contact with the landing perch) was also recorded. Balancing movements (recorded separately but summarized as a binary variable) were defined as wing flaps using both wings or asymmetrically with one wing, sideway steps, or rotation of the body (back, forth, or sideways). Safe landings were defined as landings not resulting in falls in collisions [13], and could include landings followed by balancing movements or asymmetric landings. Unsuccessful landings, i.e., landings resulting in falls or collisions, were recorded. Very few landings during the testing safe were classified as unsuccessful and thus, these data were not presented here. 
Table 1. Variables recorded from video.

\begin{tabular}{|c|c|c|}
\hline Variable & & Description \\
\hline Signal & hh:mm:ss.000 & LED on \\
\hline Take-off start & hh:mm:ss.000 & $\begin{array}{l}\text { first forward/upward movement (upward jumps) or } \\
\text { forward/downward movement (downward jumps) }\end{array}$ \\
\hline Take-off end & hh:mm:ss.000 & both feet (and toes) lose contact to take-off platform \\
\hline Landing start & hh:mm:ss.000 & first contact with the landing perch \\
\hline Landing end & hh:mm:ss.000 & $\begin{array}{l}\text { both feet on the perch and body of the hen stabilized with both } \\
\text { wings folded close to the body, head pointing forward, and tail in a } \\
\text { horizontal position }\end{array}$ \\
\hline First peck & hh:mm:ss.000 & $\begin{array}{l}\text { first peck directed towards the reward indicated by head reaching } \\
\text { the lowest position and neck feathers erecting }\end{array}$ \\
\hline
\end{tabular}

\subsubsection{Acceleration Sensors and Calculations}

The acceleration during jumps was measured using a triaxial accelerometer (MSR165 data logger, custom-made to fit in case MSR B16; size: $27 \times 16 \times 53 \mathrm{~mm}$, weight: $27 \mathrm{~g}$; MSR Electronics GmbH, Seuzach, Switzerland) with an external acceleration sensor (cable length: $20 \mathrm{~cm}$ ). The accelerometers were synchronized with video recordings and fit in a pocket at the back of a vest worn by the hens. The external sensor was placed directly on the keel (approximately $3 \mathrm{~cm}$ above the caudal tip) via the cable that was laid underneath the fabric of the vest from the back along the crop and breast. Acceleration was measured for $\mathrm{x}_{-}, \mathrm{y}-$, and $\mathrm{z}$-axis with a frequency of $800 \mathrm{~Hz}$ ( 800 measurements / sec) and a maximum sensitivity of $\pm 200 \mathrm{~g}$.

Acceleration data were transferred to the computer via dedicated software (MSR version 6.01.00) and saved as CSV-files. From the axis-specific acceleration, the combined magnitude of acceleration, i.e., the total acceleration acting on the hen was calculated:

$$
\text { acceleration }\left[\mathrm{ms}^{-2}\right]=\sqrt{a_{x}^{2}+a_{y}^{2}+a_{z}^{2}}
$$

with $a_{x}, a_{y}$, and $a_{z}$ describing acceleration in the $x, y$, and $z$ direction, respectively. Force was calculated using Newton's second law:

$$
F=m a,
$$

where $m$ was the body mass $[\mathrm{kg}]$ of the hen. Body mass was recorded with an electronic scale before and after the 16 days of testing and the average used for calculation. Peak forces [N] during take-off, flight and landing within the time frames extracted from video recordings (Table 1) were identified using R, version 3.4.2 [21].

In order to describe the accumulated forces to which a keel was exposed, the impulse for take-off, flight and landing was calculated by multiplying the average force of each phase with the respective duration:

$$
\text { impulse }[N s]=\bar{F} \Delta t
$$

\subsection{Statistical Analysis}

Statistical analysis was conducted in R, version 3.4.2 [21], using linear mixed-effect models (LMER) and generalized linear mixed-effect models (GLMER) with package 'Ime4' [22]. Model assumptions regarding normality of errors and homoscedasticity were checked by graphical analysis of residuals. For GLMER models, residuals were simulated using package 'DHARMa' [23]. Data were log or inverse $(1 / x$, inv) transformed if necessary. The final models were obtained by a stepwise-backwards reduction of the full model. Parametric bootstrap tests with package 'pbkrtest' [24] were used for model comparison with a $p$-value of $>0.05$ as a criterion of exclusion. The package 'effects' [25] was used to calculate and display model estimates. 
Data were analyzed separately for upwards and downwards jumps as conditions were not comparable directly due to different angles depending on jump direction (flat: $30^{\circ}$ up vs. $15^{\circ}$ down, steep: $60^{\circ}$ up vs. $30^{\circ}$ down). Response variables for LMER (and the applied transformation) were peak force during take-off (inv), flight (inv), and landing (inv); impulse during take-off (up: untransformed, down: $\log$ ) and landing (log); latency to jump (log); and latency to peck (log). Duration of flight was highly correlated with distance and thus, impulse was only tested for take-off and landing. The likelihood for balancing movements (binary variable) was evaluated using GLMER. Fixed effects included in all models were distance $(50 \mathrm{~cm}, 100 \mathrm{~cm})$, angle (flat, steep), hybrid (Nick Chick, Brown Nick), and all interactions. Jump number nested in condition (factor with 4 levels: $50 \mathrm{~cm} \mathrm{flat,} 50 \mathrm{~cm}$ steep, $100 \mathrm{~cm}$ flat, $100 \mathrm{~cm}$ steep) nested in hen nested in pen was used as a random effect to account for individual and pen differences and to prevent pseudo-replication. Including jump number in the random effect considered learning effects or adaptation to the specific condition within one test session. Calendar date was included as a crossed random effect to account for management and environmental effects, e.g., temperature.

\section{Results}

An overview of the results is presented in Table 2. The full data set is available in the supplementary material (Table S1).

\subsection{Peak Force at the Keel}

\subsubsection{Upward Transitions}

Peak force during take-off for upward transitions of $100 \mathrm{~cm}$ distance was greater than during take-off for upward transitions of $50 \mathrm{~cm}$ distance (estimated means (estimated $95 \%$ confidence interval): $50 \mathrm{~cm}=3.17(2.84,3.59) \mathrm{N}, 100 \mathrm{~cm}=3.61(3.19,4.17) \mathrm{N} ; p=0.027)$.

Peak force during flight was linked to an interaction of distance * angle $(p=0.037)$. Peak force during flights of $50 \mathrm{~cm}$ distance was greater if the angle was flat compared to steep (flat $=3.21$ (2.86, 3.66) $\mathrm{N}$, steep $=2.72(2.46,3.04) \mathrm{N})$, whereas during flights of $100 \mathrm{~cm}$ distance, there was no difference in peak force between flat and steep angles (flat $=3.42(3.03,3.94) \mathrm{N}$, steep $=3.51(3.08,4.06) \mathrm{N})$.

Peak force during landing was greater after transitions upwards of $100 \mathrm{~cm}$ than $50 \mathrm{~cm}$ upward transitions $(50 \mathrm{~cm}=2.93(2.64,3.29) \mathrm{N}, 100 \mathrm{~cm}=3.22(2.87,3.66) \mathrm{N} ; p=0.019)$.

\subsubsection{Downward Transition}

Peak force during take-off for downward transitions was greater in Brown Nick hens than Nick Chick hens $($ Nick Chick $=3.39(3.02,3.87) \mathrm{N}$, Brown Nick $=4.04(3.52,4.76) ; p=0.032)$.

The same pattern emerged during downward flight with Brown Nick hens experiencing greater peak force than Nick Chick hens (Nick Chick $=3.22(2.88,3.66) \mathrm{N}$, Brown Nick $=3.95(3.44,4.65) \mathrm{N}$; $p=0.008)$. In addition, peak force during downward flight was associated with a distance * angle interaction $(p=0.038)$. Although downward flight of $50 \mathrm{~cm}$ distance resulted in peak forces similar for flat and steep angles (flat $=3.32(2.91,3.88) \mathrm{N}$, steep $=3.19(2.81,3.69) \mathrm{N})$, downward flight of $100 \mathrm{~cm}$ was associated with a greater peak force if the angle was steep in comparison to a flat angle (flat $=3.45$ $(2.99,4.06)$, steep $=4.31(3.64,5.30) \mathrm{N})$.

Peak force during landing was greater after downward transitions of $100 \mathrm{~cm}$ than $50 \mathrm{~cm}(50 \mathrm{~cm}$ $=2.92(2.66,3.24) \mathrm{N}, 100 \mathrm{~cm}=3.22(2.90,3.61) \mathrm{N} ; p=0.019)$. Further, peak force during downward landing was associated with a hybrid * angle interaction of $(p=0.026)$. Peak force in landing Nick Chick hens was independent of angle (flat $=2.84(2.54,3.24) \mathrm{N}$, steep $=2.89(2.57,3.31) \mathrm{N}$ ) whereas in Brown Nick hens peak force during landing was greater after steep transitions compared to flat $($ flat $=3.23(2.85 .3 .75) \mathrm{N}$, steep $=3.31(2.91,3.86) \mathrm{N})$. 
Table 2. Overview of results including outcome variables, the variables remaining in the model after stepwise-backwards reduction (Effects), $p$-values for each variable or interaction, as well as the pattern in the results.

\begin{tabular}{|c|c|c|c|c|c|}
\hline Outcome Variable & & & Effects $^{1}$ & $p$-Value & Pattern \\
\hline \multirow{8}{*}{ Peak force } & \multirow[t]{3}{*}{ Upward } & Take-off & Distance & 0.027 & $100 \mathrm{~cm}>50 \mathrm{~cm}$ \\
\hline & & Flight & Distance * angle & 0.037 & $\begin{array}{l}50 \mathrm{~cm}: \text { flat }>\text { steep } \\
100 \mathrm{~cm}: \text { flat }=\text { steep }\end{array}$ \\
\hline & & Landing & Distance & 0.019 & $100 \mathrm{~cm}>50 \mathrm{~cm}$ \\
\hline & \multirow[t]{5}{*}{ Downward } & Take-off & Hybrid & 0.032 & Brown Nick > Nick Chick \\
\hline & & \multirow[t]{2}{*}{ Flight } & Hybrid & 0.008 & Brown Nick $>$ Nick Chick \\
\hline & & & Distance * angle & 0.038 & $\begin{array}{c}50 \mathrm{~cm}: \text { flat }=\text { steep } \\
100 \mathrm{~cm}: \text { steep > flat }\end{array}$ \\
\hline & & \multirow[t]{2}{*}{ Landing } & Distance & 0.019 & $\begin{array}{c}100 \mathrm{~cm}>50 \mathrm{~cm} \\
\text { Nick Chick: flat = steep }\end{array}$ \\
\hline & & & Hybrid * angle & 0.026 & $\begin{array}{l}\text { Brown Nick: steep }>\text { flat } \\
\text { Brown Nick }>\text { Nick Chick }\end{array}$ \\
\hline \multirow{5}{*}{ Impulse } & \multirow[t]{2}{*}{ Upward } & Take-off & Distance * angle & 0.036 & $\begin{array}{l}50 \mathrm{~cm}: \text { flat }>\text { steep } \\
100 \mathrm{~cm}: \text { flat }<\text { steep }\end{array}$ \\
\hline & & Landing & Distance * angle & 0.001 & $\begin{array}{c}50 \mathrm{~cm}: \text { flat }=\text { steep } \\
100 \mathrm{~cm}: \text { steep > flat } \\
100 \mathrm{~cm}>50 \mathrm{~cm}\end{array}$ \\
\hline & \multirow[t]{3}{*}{ Downward } & \multirow[t]{2}{*}{ Take-off } & \multirow{2}{*}{$\begin{array}{c}\text { Hybrid } \\
\text { Distance * angle }\end{array}$} & & Brown Nick $>$ Nick Chick \\
\hline & & & & 0.004 & $\begin{array}{c}50 \mathrm{~cm}: \text { flat }=\text { steep } \\
100 \mathrm{~cm}: \text { steep }>\text { flat }\end{array}$ \\
\hline & & Landing & Distance & 0.001 & $100 \mathrm{~cm}>50 \mathrm{~cm}$ \\
\hline \multirow{3}{*}{ Latency to transition } & \multirow[t]{2}{*}{ Upward } & & Hybrid & 0.016 & $\begin{array}{c}\text { Brown Nick > Nick Chick } \\
50 \mathrm{~cm} \text { : flat }=\text { steep }\end{array}$ \\
\hline & & & Distance * angle & 0.048 & $\begin{array}{c}100 \mathrm{~cm}: \text { steep }>\text { flat } \\
100 \mathrm{~cm}>50 \mathrm{~cm}\end{array}$ \\
\hline & Downward & & $\begin{array}{l}\text { Distance } \\
\text { Angle }\end{array}$ & $\begin{array}{l}0.001 \\
0.001\end{array}$ & $\begin{array}{c}100 \mathrm{~cm}>50 \mathrm{~cm} \\
\text { Steep }>\text { flat }\end{array}$ \\
\hline \multirow{2}{*}{ Balancing movements } & Upward & & Distance * angle & 0.001 & $\begin{array}{l}50 \mathrm{~cm}: \text { flat }=\text { steep } \\
100 \mathrm{~cm}: \text { steep }>\text { flat }\end{array}$ \\
\hline & Downward & & Distance & 0.0001 & $100 \mathrm{~cm}>50 \mathrm{~cm}$ \\
\hline \multirow{3}{*}{ Latency to first peck } & \multicolumn{2}{|l|}{ Upward } & Distance * angle & 0.001 & $\begin{array}{l}50 \mathrm{~cm}: \text { flat }=\text { steep } \\
100 \mathrm{~cm}: \text { steep > flat }\end{array}$ \\
\hline & \multirow[t]{2}{*}{ Downward } & & Hybrid & 0.034 & $\begin{array}{c}\text { Nick Chick > Brown Nick } \\
50 \mathrm{~cm} \text { : flat }=\text { steep }\end{array}$ \\
\hline & & & Distance * angle & 0.006 & $\begin{array}{l}100 \mathrm{~cm} \text { : steep > flat } \\
100 \mathrm{~cm}>50 \mathrm{~cm}\end{array}$ \\
\hline
\end{tabular}

${ }^{1}$ Variables remaining in the model after stepwise-backwards reduction.

\subsection{Impulse}

\subsubsection{Upward Transition}

Impulse (accumulated forces at the keel) during upward take-off was associated with a distance * angle interaction $(p=0.036)$. During take-off for transitions of $100 \mathrm{~cm}$, impulse was slightly lower in flat than steep angles (flat $=0.29(0.25,0.33) \mathrm{Ns}$, steep $=0.27(0.22,0.31) \mathrm{Ns})$. During take-off for transitions of $50 \mathrm{~cm}$, flat angles were linked to a greater impulse than steep (flat $=0.30(0.26,0.34) \mathrm{Ns}$, steep $=0.27(0.22,0.31) \mathrm{Ns})$.

Impulse during landing was linked with an interaction of distance ${ }^{*}$ angle $(p=0.001)$. Landing after $50 \mathrm{~cm}$ distance transitions resulted in a similar impulse for flat and steep angles (flat $=1.41(1.23$, 1.62) Ns, steep $=1.42(1.23,1.64) \mathrm{Ns})$. Impulse during landing after $100 \mathrm{~cm}$ distance transitions was higher than during landing after $50 \mathrm{~cm}$ transitions and increased in steep angles compared to flat angles (flat $=1.60(1.339,1.85) \mathrm{Ns}$, steep $=2.32(2.01,2.68) \mathrm{Ns}$ ). 


\subsubsection{Downward Transition}

Impulse during downward take-off was higher in Brown Nick hens $(0.53(0.46,0.61) \mathrm{Ns})$ than in Nick Chick hens $(0.39(0.34,0.45) \mathrm{Ns} ; p=0.018)$. We further found a distance * angle interaction relating to impulse during downward take-off $(p=0.004)$. Impulse during take-off for transitions of $50 \mathrm{~cm}$ was similar for flat and steep angles (flat $=0.45(0.40,0.52) \mathrm{Ns}$, steep $=0.47(0.41,0.54) \mathrm{Ns}$ ), whereas transitions of $100 \mathrm{~cm}$ and steep angles resulted in higher impulse than transitions of $100 \mathrm{~cm}$ and flat angles (flat $=0.36(0.32,0.42) \mathrm{Ns}$, steep $=0.51(0.45,0.59) \mathrm{Ns}$ ).

During landing after downward transitions, impulse was higher after transitions of $100 \mathrm{~cm}$ compared to transitions of $50 \mathrm{~cm}(50 \mathrm{~cm}=1.59(1.37,1.86) \mathrm{Ns}, 100 \mathrm{~cm}=2.04(1.75,2.38) \mathrm{Ns} ; p=0.001$, Figure 4).

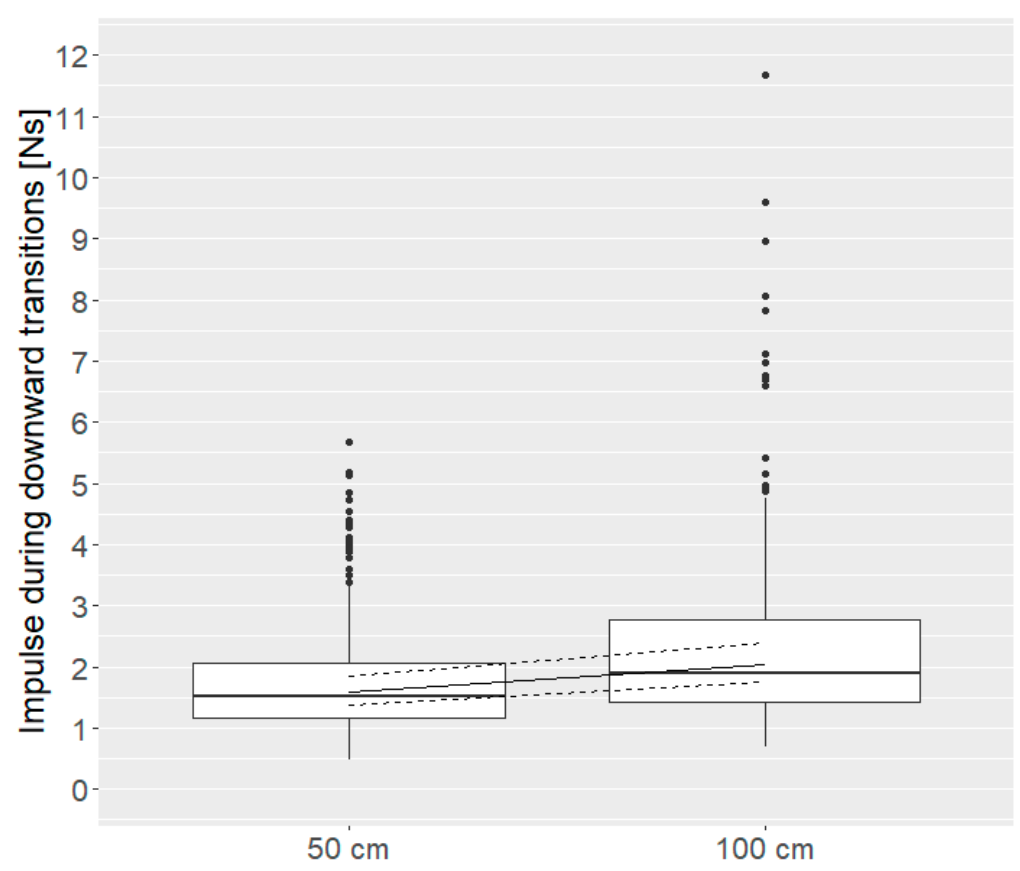

Figure 4. Impulse during downward landing (Ns) for $50 \mathrm{~cm}$ and $100 \mathrm{~cm}$ distance (distance: $p=0.001$ ). Boxes show medians, lower and upper interquartile range. Whiskers indicate 1.5 times the interquartile range. In addition, model estimates with estimated means (solid line) and $95 \%$ confidence intervals (dashed lines) are shown.

\subsection{Latency to Transition}

\subsubsection{Upward Transition}

Latency to transition between the platform and perch was greater in Brown Nick hens than Nick Chick hens (Nick Chick $=1.38(1.07,1.80)$ sec, Brown Nick $=2.78(2.16,3.59)$ sec; $p=0.016)$. Latency to transition was also associated with a distance * angle interaction $(p=0.048$, Figure 5$)$. Latency to transition upward was similar for flat and steep angles of $50 \mathrm{~cm}$ (flat $=1.44(1.16,1.78)$ sec, steep $=$ $1.38(1.11,1.71) \mathrm{sec})$. Latency to transition $100 \mathrm{~cm}$ was greater than a distance of $50 \mathrm{~cm}$, whereas steep angles for $100 \mathrm{~cm}$ upward transitions were associated with increased latency compared to flat angles $($ flat $=2.61(2.10,3.24) \mathrm{sec}$, steep $=3.32(2.66,4.15) \mathrm{sec})$. 


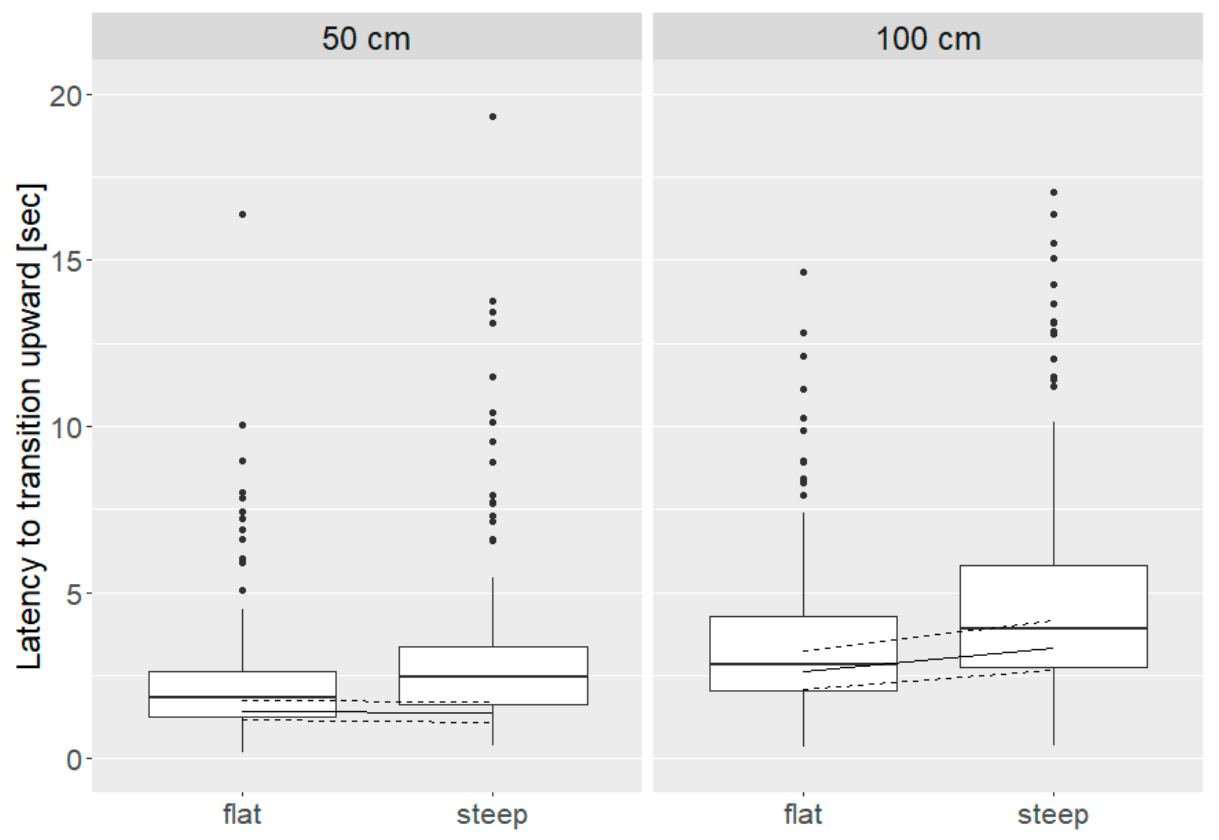

Figure 5. Latency to transition (sec) for distances of $50 \mathrm{~cm}$ and $100 \mathrm{~cm}$ and flat and steep angles (distance ${ }^{*}$ angle: $p=0.048$ ). Boxes show medians, lower and upper interquartile range. Whiskers indicate 1.5 times the interquartile range. In addition, model estimates with estimated means (solid line) and 95\% confidence intervals (dashed lines) are shown.

\subsubsection{Downward Transition}

Latency to transition downward was higher for $100 \mathrm{~cm}$ transitions $(3.89(3.11,4.87) \mathrm{sec})$ than $50 \mathrm{~cm}$ $(2.31(1.85,2.89) \mathrm{sec} ; p=0.001)$. Latency to transition downward was further linked to angle $(p=0.001)$, with a greater latency to transition with steep $(3.41(2.72,4.26) \mathrm{sec})$ than flat angles $(2.58(2.06,3.23) \mathrm{sec})$.

\subsection{Balancing Movements at Landing}

\subsubsection{Upward Transition}

The likelihood to perform balancing movements was associated with a distance * angle interaction $(p=0.0001$; Figure 6). Hens were similarly likely to perform balancing movements after $50 \mathrm{~cm}$ distance transitions of flat and steep angles (flat $=23.2(16.0,32.5) \%$, steep $=17.0(11.0,25.2) \%$ ) as well as $100 \mathrm{~cm}$ distance transitions of flat angles $(21.5(14.4,30.9) \%)$, whereas the likelihood to perform balancing movements was greater after transitions characterized by $100 \mathrm{~cm}$ and steep angles $(57.9(45.9,68.9) \%)$.

\subsubsection{Downward Transition}

Hens were more likely to perform balancing movements after downward transitions of $100 \mathrm{~cm}$ than after $50 \mathrm{~cm}(50 \mathrm{~cm}=35.6(30.2,41.3) \%, 100 \mathrm{~cm}=53.9(47.8,60.0) \% ; p=0.0001)$.

\subsection{Latency to First Peck}

\subsubsection{Upward Transition}

After upward transitions, the latency to peck was linked to a distance * angle interaction $(p=0.001$; Figure 7) with similar values after $50 \mathrm{~cm}$ flat and steep angle transitions (flat $=0.97(0.89,1.07) \mathrm{sec}$, steep $=1.01(0.92,1.11) \mathrm{sec})$ and $100 \mathrm{~cm}$ flat transitions $(1.05(0.95,1.15) \mathrm{sec})$. In contrast, the latency to peck was greater after $100 \mathrm{~cm}$ steep transitions $(1.31(1.19,1.45) \mathrm{sec})$. 


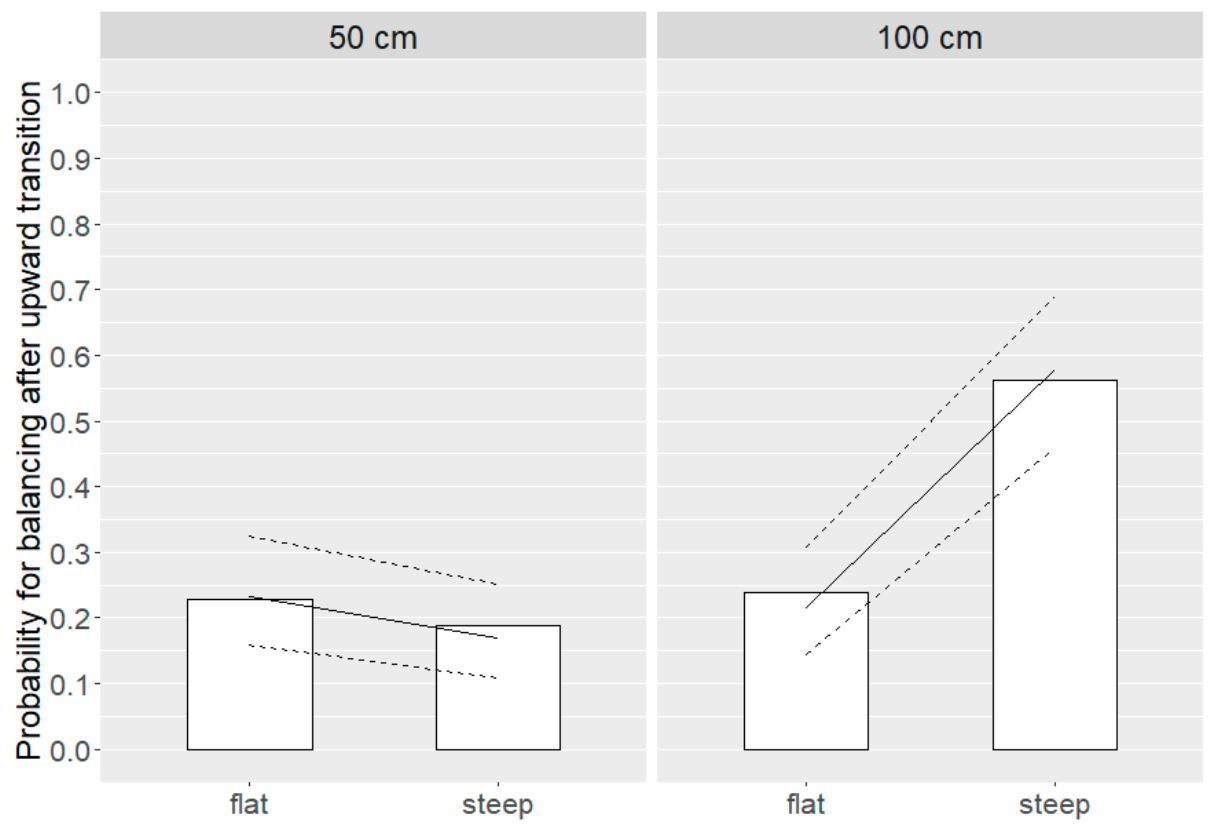

Figure 6. Probability for balancing movements after upward transitions of $50 \mathrm{~cm}$ and $100 \mathrm{~cm}$ distance and flat and steep angles (distance ${ }^{*}$ angle: $p=0.0001$ ). Bars represent the ratio of hens performing balancing movements after transitions of a specific condition. In addition, model estimates with estimated means (solid line) and $95 \%$ confidence intervals (dashed lines) are shown.

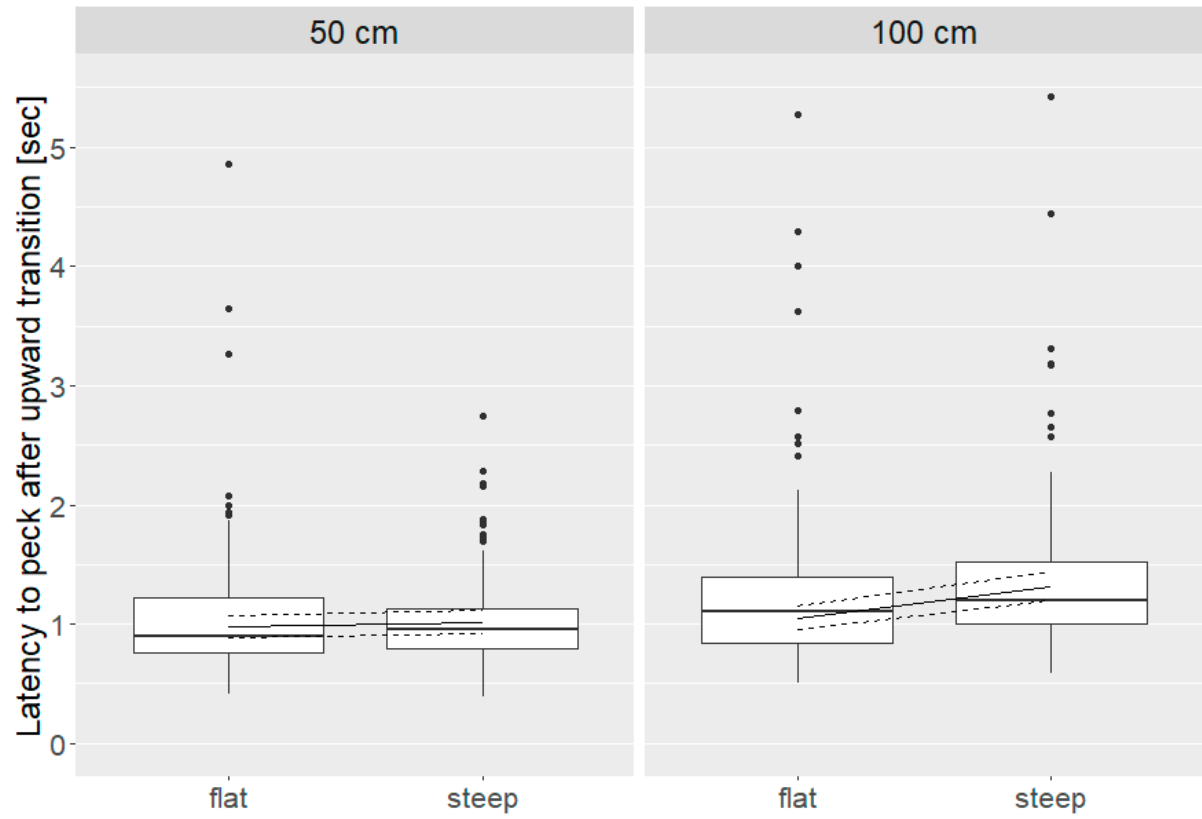

Figure 7. Latency to peck (sec) after upward transitions of $50 \mathrm{~cm}$ and $100 \mathrm{~cm}$ distance and flat and steep angle transitions (distance ${ }^{*}$ angle: $p=0.001$ ). Boxes show medians, lower and upper interquartile range. Whiskers indicate 1.5 times the interquartile range. In addition, model estimates with estimated means (solid line) and $95 \%$ confidence intervals (dashed lines) are shown.

\subsubsection{Downward Transition}

Latency to peck after downward landing was greater in Nick Chick than Brown Nick hens (Nick Chick $=1.11(1.02,1.20) \mathrm{sec}$, Brown Nick $=0.94(0.86,1.02) \mathrm{sec} ; p=0.034)$. We found an interaction of distance * angle relating to the latency to peck after downward transitions $(p=0.006)$. Latency to peck was similar after downward, $50 \mathrm{~cm}$ transitions for flat, and steep angles (flat $=0.95(0.88,1.03)$ 
$\mathrm{sec}$, steep $=0.92(0.85,0.99) \mathrm{sec})$. Latency to peck was greater after downward transitions of $100 \mathrm{~cm}$, especially if the angle was steep (flat $=1.06(0.98,1.14) \mathrm{sec}$, steep $=1.22(1.12,1.32) \mathrm{sec})$.

\section{Discussion}

The aim of this study was to assess the effect of perch positioning on laying hen locomotion and the resulting energy experienced at the keel. As predicted, we found that longer distances and steeper angles-especially during downward transitions-resulted in an increased peak force and impulse at the keel and were more difficult for the hens to navigate based on longer latency to transition, higher likelihood for balancing at landing, and a higher latency to peck at the reward after landing. Our results indicate that distance and angle between take-off and landing structure could contribute to the high keel bone fracture prevalence observed in complex aviary systems. Accumulated forces during routine behaviors and the risk for high-impact collisions due to difficulties in transitions between perches might be the two main mechanisms associated with perch positioning and its relation to keel bone fracture risk.

During observations of flight and landing, transitions that were characterized as longer and steeper in either the up or down orientation appeared to be more difficult for hens as indicated by the greater latency to transition and the behavior after contacting the perch, i.e., time to peck and balancing. Our findings generally agree with these of others $[7,8,10,11]$. The current study used hens that were trained and thus familiar with the testing paradigm which allows for a greater consideration of the factors that make certain transitions more difficult. Specifically, the increased latency to transition with steeper angles could suggest that hens required a greater amount of time to position themselves and cognitively process the information needed for flight including the position of the landing perch and/or thrust required for take-off. Moinard et al. [26] calculated trajectories during take-off and landing by observing the eye position of hens in experimental flight and suggested that hens were gathering visual information about the perch to determine needed take-off thrust. Latencies in downward movements in our study were approximately 0.9 s greater than upward movements, which also agrees with existing literature that the former are more demanding $[7,8]$.

Once the hen has taken off, landing will involve a separate set of processes as the hen seeks to adjust her vertical position, speed, and extension of the feet to make contact with the landing surface [27]. The duration of balancing behaviors and latency to peck at the food reward in the current study was increased in longer and steeper transitions suggesting the greater difficulty of these movements. Moinard et al. [26] suggested the greater variation in eye position relative to the perch during landing in more challenging transitions could relate to difficulty adjusting the hen's position during flight. Our observations once the hen has landed could be an extension of those compensating behaviors performed in the approach period as the hen continues to adjust her position on the perch. Specifically, if the head is positioned too far forward over the perch or not far enough as she makes initial contact, the hen must perform balancing movements (e.g., use her wings or shift her legs) to ensure she does not topple over. The finer elements of landing behavior may help to explain previous findings where the reduced slipperiness of different perch types was believed to improve landings [10] and require less balance movements [28].

The load experienced by the keel bone (represented by impulse and peak force during take-off, flight, and landing) was greater in magnitude during landing following longer and steeper transitions as expected. The force acting on the whole hen during landing has been shown to be considerably greater (mean peak force: 81.0-106.9 $\mathrm{N}$ [17]) than the peak force measured directly at the keel in the present study $(2.92-4.04 \mathrm{~N})$ likely because the majority of kinetic energy during a safe landing is absorbed by the feet and legs. Unsafe landings resulting in collisions will result in much greater load at the keel with accelerations of $>100 \mathrm{G}(=150 \mathrm{~N}$ for a hen of $1.5 \mathrm{~kg}$ bodyweight $[18,29])$, but it is not clear whether these forces are directly related to the occurrence of keel bone fractures. Future efforts will need to determine the upper threshold of fracture risk in terms of collision energy and other related factors during events resulting in trauma, e.g., collisions. One method to determine such 
thresholds would be an impact testing paradigm used by our group in a variety of situations [30-32], though conditions would need to be comparable.

Hens of the current study experienced a limited number of poor landings, and only safe transitions without falls or collisions were considered. On one hand, the relatively low energies the keel was required to absorb during controlled transitions may represent a 'safe' quantity of energy that the keel can experience. On the other hand, forces applied to the keel during controlled movements between perches as observed in the present study are less likely to cause trauma-related fractures, although could contribute to fatigue fractures which occur when normal bone is exposed to repeated stress [15]. Supporting this position, recent information has suggested that fractures could result from events other than trauma-related collisions (reviewed by [33]). Casey-Trott et al. [34] suggested that greenstick fractures (i.e., incomplete, bending fractures commonly found in developing bone) might result from routine behaviors, while Harlander-Matauschek et al. [6] specified the need to investigate low energy non-collision events as a cause of fracture. Evidence that many fractures lack the pathological signs of traumatic injury have been reported [14], with similar findings elsewhere [35] though the latter authors' distinction between fractures and deviations of the keel was not clear. Taken together, these reports highlight a need to understand the nature of the forces to which the keel is exposed and how this might lead to non-traumatic fractures.

Overall, both accumulated forces as well as difficulties in transitions between perches seem to be related to angle and distance between elements of the housing system as well as the direction of movement. Our results are relevant for commercial conditions, especially aviaries, due to several reasons. First, laying hens housed in aviaries are required to use aerial locomotion in order to move vertically through their environment and to reach all resources. As a result of the spatial distribution of resources in aviary systems, hens cannot avoid applying repeated load on their keel bones when using their flight muscles [36], and thus have to expose their keel to accumulated forces and corresponding risk for stress fractures when accessing feed, water, nest boxes, perches, or litter. Whereas these forces might not be problematic in healthy hens, weakened bones due to high egg laying rates [37] or other disease conditions [33] would contribute to increased fracture susceptibility and the risk for insufficiency fractures (when stress is applied to a bone with deficient elastic resistance [16]). Second, we found that hens responded differently to perch positioning depending on strain (i.e., brown vs. white hens). Strain-specific differences in locomotion and navigation abilities within different aviary designs relate to keel fracture frequency and severity [38], therefore the design of commercially available aviary systems might need to consider the used genetic line. Third, our results were obtained from hens with unfractured keels based on palpation. Given that keel bone fractures affect hen mobility [39-41], the high fracture prevalence found in older birds kept in experimental and commercial systems [5] might amplify the negative effect of steep angles and long distances on transition success. Fourth, hens in the present study were carefully trained in order to transition between all perch positions successfully. Considering that angles and distances of hen transitions in commercial systems are often steeper or longer than the present study (up to $105 \mathrm{~cm}$ diagonal distance and $80^{\circ}$ between tiers in Swiss aviary systems [42]), accumulated forces and the risk for trauma-related fractures is presumably higher if hens are not familiar with their environment. The transition between rearing and layer environments and the period immediately following should be considered in the development of keel bone fractures as hens are usually exposed to a higher and more complex system than they are experienced with (reviewed in [43]).

In order to reduce the load on the keel bone which could result in keel bone fracture occurrence, we recommend distances and angles for paths within a housing system not to exceed $50 \mathrm{~cm}$ and $30^{\circ}$ as these perch positions have been shown to be more successfully navigated than steeper angles and longer distances in previous studies. However, distances and angles below $50 \mathrm{~cm}$ and $30^{\circ}$, respectively, did not avoid falls in all cases [8,9]. Accordingly, increased distance between rows of an aviary can be a risk factor for keel bone fractures [44]. More specific recommendations are needed for multi-level housing system such as aviaries with increased difficulty in transitioning between levels. Periods 
of increased local density in certain areas (i.e., upper perches immediately before and during lights out [45]) and other hens being present at the take-off or landing site are likely to decrease the chance of a successful landing [46]. In addition, dimmed light during dawn and dusk can affect transition accuracy and thus, the risk for falls [7,47] though lighting conditions only affect landing accuracy and the latency to jump when the intensity is very low (i.e., below 2 Lux $[7,47])$. Alternative types of inter-tier movement such as ramps have been shown to be beneficial regarding both vertical space use [48] as well as keel bone fracture development [13,49]. The specific forces hens experience using ramps and the potential benefit to promoting bone health should be evaluated.

\section{Conclusions}

Although we cannot state how the observed forces relate to the risk for keel bone fractures directly, the results of the present study indicate that perch positioning affects accumulated forces at the keel during take-off, flight and landing. Moreover, the associations between perch position and locomotion behavior (e.g., longer latency to jump, higher likelihood to perform balancing movements, and longer latency to peck after transitions between steep angles and long distances) indicate that perch positioning affects the hen's ability to successfully navigate between perches. Our results show that optimizing perch positioning is crucial for successful transitions within the housing system and could be an approach to reduce keel bone fracture prevalence in commercial laying hens housed in aviaries.

Supplementary Materials: The following are available online at http://www.mdpi.com/2076-2615/10/7/1223/s1, Table S1: full data set.

Author Contributions: Conceptualization, C.R., A.S., and M.J.T.; methodology, C.R.; data collection, C.R. and A.K.R.; data processing, C.R.; formal analysis, C.R.; writing-original draft preparation, C.R. and M.J.T.; writing-review and editing, C.R., A.K.R., A.S., and M.J.T.; visualization, C.R.; supervision, A.S. and M.J.T.; project administration, M.J.T.; funding acquisition, M.J.T. All authors have read and agreed to the published version of the manuscript.

Funding: This project was funded by the Federal Food Safety and Veterinary Office FSVO (project number 2.15.05).

Acknowledgments: We thank the Aviforum staff for excellent animal care. We are grateful to Abdulsatar Rahman for help with hen training and Gion Michel for video and MSR data processing and analysis. Many thanks to Markus Schwab and Mischa Müller for help with the pilot experiment, final pen set-up, the construction of the rewarding apparatus, as well as technical assistance.

Conflicts of Interest: The authors declare no conflicts of interest.

\section{Appendix A. - Habituation and Selection Criteria}

After a week of habituation to the new environment with the test pen being continuously accessible, hens were habituated to catching, handling and isolation in the test pen. On five days of the first isolation week (17 weeks of age), all hens were caught individually by grabbing both legs and carried to the test pen by holding them under the breast and around the wings with both hands. Hens were isolated in the test pen in groups of two for $10 \mathrm{~min}$. On five days of the second isolation week (18 weeks of age), all hens were isolated alone in the test pen for five minutes. During isolation, hens were observed and notes on individual behavior (e.g., vocalization, activity, and escape attempts) were taken. If individual hens did not habituate to isolation and manifested behavior indicative of high stress levels during these weeks, they were excluded from further observations and testing. Indicators of high stress levels were: vocalization, excessive activity, escape attempts (jumps/flight against the walls), and positioning themselves in front of the door to the home pen. Hens not selected for additional training remained in the home pens without further exposure to handling and training.

For habituation to the rewarding apparatus, a dummy rewarding apparatus was placed in all eight test pens from the first day of population on (16 weeks of age). The dummy rewarding apparatus was the same size and material as the rewarding apparatus, but the flap covering the reward was constantly open. Wheat grains were placed in the dummy rewarding apparatus at multiple but irregular times, i.e., 3-10 times a week thus hens learned to access the reward from the apparatus. 
At 19 weeks of age, the dummy rewarding apparatus was replaced by a functioning rewarding apparatus and placed in the middle of the home pen once a day. The experimenter would stand in a corner of the home pen opening and closing the apparatus from distance using the switch. The number of feeding bouts per hen and the number of approaches to the apparatus while the reward was not accessible, i.e., the flap was closed, and was recorded for each individual hen. After opening the apparatus 5-8 times, the $2-4$ hens showing the most feeding bouts and waiting most often in front of the rewarding apparatus were caught and isolated in the test pen. The procedure was repeated until all hens had been feeding at the apparatus at least once, and hens were ranked according to the order they were removed from the group. This protocol was applied for each pen on five days. By the end of the week, the ten hens with the overall highest rank per pen (i.e., the birds that were on average isolated in the test pen the fastest) were selected as focal hens.

\section{Appendix B. - Training Procedure}

Appendix B.1. Stage 1: Feeding from Platform (20 Weeks of Age)

Hens were placed on the take-off platform directly in front of the rewarding apparatus (landing perch removed), both installed at $1 \mathrm{~m}$ above ground. The reward was presented 5-8 times by operating the switch to open the flap. Hens were excluded from further training if they did not feed at least three times for 5 sec on three consecutive days.

\section{Appendix B.2. Stage 2: Feeding from Perch (21 Weeks of Age)}

Hens were placed on the landing perch directly in front of the rewarding apparatus, both installed at $1 \mathrm{~m}$ above ground. The reward was presented 5-8 times by operating the switch to open the flap. Hens were excluded from further training if they did not feed at least three times for $5 \mathrm{sec}$ on three consecutive days.

\section{Appendix B.3. Stage 3: Step from Platform to Perch (22 Weeks of Age)}

Hens were required to step from the platform to the perch (installed $1 \mathrm{~m}$ above ground) in order to get access to the reward. The reward was presented immediately after the hen was placed on the platform and the hen was allowed to feed for $5 \mathrm{sec}$ after stepping on the perch. After $5 \mathrm{sec}$ of feeding, the flap was closed using the switch and hen was placed back on the platform. Hens were excluded from further training if they did not step from platform to the perch followed by 5 sec of feeding at least three times on three consecutive days.

\section{Appendix B.4. Stage 4: Horizontal Distance (23 Weeks of Age)}

Distance between platform and perch (installed $1 \mathrm{~m}$ above ground) was increased within and between training sessions (e.g., first day, first jump: $20 \mathrm{~cm}$, last jump: $40 \mathrm{~cm}$; last day, first jump: $50 \mathrm{~cm}$, last jump: $100 \mathrm{~cm}$ ). Difficulty (i.e., distance) was increased hen-individually to avoid unsuccessful landings and falls. Hens were excluded from further training if they did not jump at least three times to the perch followed by 5 sec of feeding on all days.

\section{Appendix B.5. Stage 5: Angles upwards (24 Weeks of Age)}

Hens were introduced to the take-off platform for upwards movements (60 $\mathrm{cm}$ above ground). Vertical height between of the landing perch was increased with each training session. Within each training session, the landing perch remained at the same height but horizontal distance between take-off platform and landing perch was varied, resulting in different angles and diagonal distances for upward jumps. Hens were excluded from further training if they did not jump at least three times to the perch followed by 5 sec of feeding on all days. 
Appendix B.6. Stage 6: Angles downwards (25 Weeks of Age)

Hens were introduced to the take-off platform for downwards movements ( $135 \mathrm{~cm}$ above ground). Vertical height between of the landing perch was increased with each training session. Within each training session, the landing perch remained at the same height but horizontal distance between take-off platform and landing perch was varied, resulting in different angles and diagonal distances for downward jumps. Hens were excluded from further training if they did not jump at least three times to the perch followed by 5 sec of feeding on all days.

\section{Appendix B.7. Stage 7: Varying Conditions (26 Weeks of Age)}

Direction (upward and downward) and both vertical and horizontal distance were varied among training sessions. This last week of training served to habituate the hens to changing conditions, e.g., upward jumps on one day and downward jumps on the next day. For habituation, all testing equipment (accelerometer, video camera, screen, and laptop) was installed and operational, but not recording. Hens were excluded from further training if they did not jump at least three times to the perch followed by $5 \mathrm{sec}$ of feeding on all days.

\section{Appendix B.7.1. General Notes}

If a hen jumped before the signal was initiated, no reward was presented, and the hen was placed back on the take-off platform. If a fall occurred, the hen was placed back on the perch to feed. Training was then repeated until the hen jumped and landed successfully. If necessary, difficulty was decreased (e.g., shorter distance or smaller angle) for this training session until the hen was willing to jump again. If a hen jumped to the floor instead of the landing perch, she was placed back on the platform and the signal was initiated again. After two jumps to the ground, hens were placed back into the home pen and this training session was considered unsuccessful. If a hen did not jump to the landing perch (latency $>20 \mathrm{sec}$ ), she was grabbed and lifted up before being placed back on the platform and exposed to the signal again.

\section{Appendix B.7.2. Determining Time Stamps}

As the camera recorded with a frequency of $240 \mathrm{fps}$, an image frame was available every 4 th millisecond. However, as the maximum frequency of the laptop and thus, the screen was restricted to $120 \mathrm{fps}$ (i.e., half the frequency of the camera), the time stamp including milliseconds was visible on every second frame of the video only. If an event (e.g., signal) coincided with a frame not showing milliseconds, the exact time was calculated from the previous frame by adding 4 milliseconds.

\section{References}

1. Karcher, D.M.; Mench, J.A. Overview of commercial poultry production systems and their main welfare challenges. In Advances in Poultry Welfare Science; Mench, J.A., Ed.; Woodhead Publishing: Camridge, UK, 2018; pp. 3-25.

2. Cooper, J.J.; Albentosa, M.J. Behavioural Priorities of Laying Hens. Avian Poult. Biol. Rev. 2003, 14, 127-149. [CrossRef]

3. Weeks, C.A.; Nicol, C.J. Behavioural needs, priorities and preferences of laying hens. World's Poult. Sci. J. 2006, 62, 296-307. [CrossRef]

4. Wilkins, L.J.; McKinstry, J.L.; Avery, N.C.; Knowles, T.G.; Brown, S.N.; Tarlton, J.; Nicol, C.J. Influence of housing system and design on bone strength and keel bone fractures in laying hens. Vet. Rec. 2011, 169, 414. [CrossRef]

5. Rufener, C.; Makagon, M.M. Keel bone fractures in laying hens: A systematic review of prevalence across age, housing systems, and strains. J. Anim. Sci. 2020, in press.

6. Harlander-Matauschek, A.; Rodenburg, T.B.; Sandilands, V.; Tobalske, B.W.; Toscano, M.J. Causes of keel bone damage and their solutions in laying hens. World's Poult. Sci. J. 2015, 71, 461-472. [CrossRef] 
7. Moinard, C.; Statham, P.; Haskell, M.J.; McCorquodale, C.; Jones, R.B.; Green, P.R. Accuracy of laying hens in jumping upwards and downwards between perches in different light environments. Appl. Anim. Behav. Sci. 2004, 85, 77-92. [CrossRef]

8. Scott, G.B.; Lambe, N.R.; Hitchcock, D. Ability of laying hens to negotiate horizontal perches at different heights, separated by different angles. Br. Poult. Sci. 1997, 38, 48-54. [CrossRef] [PubMed]

9. Lambe, N.R.; Scott, G.B.; Hitchcock, D. Behaviour of Laying Hens Negotiating Perches at Different Heights. Anim. Welf. 1997, 6, 29-41.

10. Scholz, B.; Kjaer, J.B.; Schrader, L. Analysis of landing behaviour of three layer lines on different perch designs. Br. Poult. Sci. 2014, 55, 419-426. [CrossRef]

11. Scott, G.B.; Parker, C.A.L. The ability of laying hens to negotiate between horizontal perches. Appl. Anim. Behav. Sci. 1994, 42, 121-127. [CrossRef]

12. Scott, G.B.; Hughes, B.O.; Lambe, N.R.; Waddington, D. Ability of laying hens to jump between perches: Individual variation and the effects of perch separation and motivation on behaviour. Br. Poult. Sci. 1999, 40, 177-184. [CrossRef]

13. Stratmann, A.; Fröhlich, E.K.F.; Gebhardt-Henrich, S.G.; Harlander-Matauschek, A.; Würbel, H.; Toscano, M.J. Modification of aviary design reduces incidence of falls, collisions and keel bone damage in laying hens. Appl. Anim. Behav. Sci. 2015, 165, 112-123. [CrossRef]

14. Thøfner, I.; Hougen, H.P.; Villa, C.; Lynnerup, N.; Christensen, J.P. Pathological characterization of keel bone fractures in laying hens does not support external trauma as the underlying cause. PLoS ONE 2020, 15, 1-15. [CrossRef] [PubMed]

15. Anderson, M.W.; Greenspan, A. Stress Fractures. Radiology 1996, 199, 1-12. [CrossRef] [PubMed]

16. Knapp, T.P.; Garrett, W.E. Stress Fractures: General Concepts. Clin. Sports Med. 1997, 16, 339-356. [CrossRef]

17. Banerjee, D.; Daigle, C.L.; Dong, B.; Wurtz, K.; Newberry, R.C.; Siegford, J.M.; Biswas, S. Detection of jumping and landing force in laying hens using wireless wearable sensors. Poult. Sci. 2014, 93, 2724-2733. [CrossRef]

18. Baker, S.L.; Robison, C.I.; Karcher, D.M.; Toscano, M.J.; Makagon, M.M. Keel impacts and associated behaviors in laying hens. Appl. Anim. Behav. Sci. 2020, 222, 104886. [CrossRef]

19. Rentsch, A.K.; Rufener, C.B.; Spadavecchia, C.; Stratmann, A.; Toscano, M.J. Laying Hens' Mobility Is Impaired by Keel Bone Fractures Though Effect Is Not Reversed by Paracetamol Treatment. Appl. Anim. Behav. Sci. 2019. [CrossRef]

20. Casey-Trott, T.; Heerkens, J.L.T.; Petrik, M.; Regmi, P.; Schrader, L.; Toscano, M.J.; Widowski, T. Methods for assessment of keel bone damage in poultry. Poult. Sci. 2015, 94, 2339-2350. [CrossRef]

21. R Core Team. R: A Language and Environment for Statistical Computing; R Foundation for Statistical Computing: Vienna, Austria, 2017; Available online: http://www.r-project (accessed on 27 May 2020).

22. Bates, D.; Maechler, M.; Bolker, B.; Walker, S. Fitting Linear Mixed-Effects Models Using lme4. J. Stat. Softw. 2015, 67, 1-48. [CrossRef]

23. Hartig, F. DHARMa: Residual Diagnostics for Hierarchical (Multi-Level/Mixed) Regression Models. R Package Version 0.1.6. 2018. Available online: https://cran.r-project.org/package=DHARMa (accessed on 27 May 2020).

24. Halekoh, U.; Højsgaard, S. A Kenward-Roger Approximation and Parametric Bootstrap Methods for Tests in Linear Mixed Models-The R Package pbkrtest. J. Stat. Softw. 2014, 59, 1-30. [CrossRef]

25. Fox, J. Effect Displays in R for Generalised Linear Models. J. Stat. Softw. 2003, 8, 1-27. [CrossRef]

26. Moinard, C.; Statham, P.; Green, P.R. Control of landing flight by laying hens: Implications for the design of extensive housing systems. Br. Poult. Sci. 2004, 45, 578-584. [CrossRef] [PubMed]

27. Green, P.; Moinard, C.; Statham, P. Control of landing flight in laying hens: What are the effects of domestication? In Welfare of the Laying Hen; Perry, G.C., Ed.; CABI Publishing: Wallingford, UK, 2004; p. 403.

28. Pickel, T.; Scholz, B.; Schrader, L. Perch material and diameter affects particular perching behaviours in laying hens. Appl. Anim. Behav. Sci. 2010, 127, 37-42. [CrossRef]

29. Mackie, N.; Stratmann, A.; Toscano, M.J.; Tarlton, J.F. Using tri-axial accelerometers to determine hazardous pathways for laying hens in aviaries. In Proceedings of the Xth European Symposium on Poultry Welfare, Ploufragan, France, 19-22 June 2017; Volume 97.

30. Candelotto, L.; Stratmann, A.; Gebhardt-Henrich, S.G.; Rufener, C.; Van De Braak, T.; Toscano, M.J. Susceptibility to keel bone fractures in laying hens and the role of genetic variation. Poult. Sci. 2017, 96. [CrossRef] [PubMed] 
31. Toscano, M.J.; Wilkins, L.J.; Millburn, G.; Thorpe, K.; Tarlton, J.F. Development of an Ex Vivo Protocol to Model Bone Fracture in Laying Hens Resulting from Collisions. PLoS ONE 2013, 8, e66215. [CrossRef] [PubMed]

32. Toscano, M.J.; Booth, F.; Richards, G.; Brown, S.N.; Karcher, D.M.; Tarlton, J.F. Modeling collisions in laying hens as a tool to identify causative factors for keel bone fractures and means to reduce their occurrence and severity. PLOS ONE 2018, 13, e0200025. [CrossRef]

33. Toscano, M.J.; Dunn, I.C.; Christensen, J.-P.; Petow, S.; Kittelsen, K.; Ulrich, R. Explanations for keel bone fractures in laying hens: Are there explanations in addition to elevated egg production? Poult. Sci. 2020. [CrossRef]

34. Casey-Trott, T.M.; Guerin, M.T.; Sandilands, V.; Torrey, S.; Widowski, T.M. Rearing system affects prevalence of keel-bone damage in laying hens: A longitudinal study of four consecutive flocks. Poult. Sci. 2017, 96, 2029-2039. [CrossRef]

35. Scholz, B.; Rönchen, S.; Hamann, H.; Hewicker-Trautwein, M.; Distl, O. Keel bone condition in laying hens: A histological evaluation of macroscopically assessed keel bones. Berl. Munch. Tierarztl. Wochenschr. 2008, 121, 89-94.

36. Sisson, S.; Grossman, J.D.; Getty, R. Sisson and Grossman's The Anatomy of the Domestic Animals, 5th ed.; Getty, R., Ed.; Saunders: Philadelphia, PA, USA, 1975.

37. Eusemann, B.K.; Patt, A.; Schrader, L.; Weigend, S.; Thöne-Reineke, C.; Petow, S. The Role of Egg Production in the Etiology of Keel Bone Damage in Laying Hens. Front. Vet. Sci. 2020, 7. [CrossRef]

38. Stratmann, A.; Fröhlich, E.K.F.; Gebhardt-Henrich, S.G.; Harlander-Matauschek, A.; Würbel, H.; Toscano, M.J. Genetic selection to increase bone strength affects prevalence of keel bone damage and egg parameters in commercially housed laying hens. Poult. Sci. 2016, 95, 975-984. [CrossRef]

39. Rufener, C.; Abreu, Y.; Asher, L.; Berezowski, J.; Maximiano Sousa, F.; Stratmann, A.; Toscano, M.J. Keel bone fractures are associated with individual mobiltiy of laying hen in aviary systems. Appl. Anim. Behav. Sci. 2019, 217, 48-56. [CrossRef]

40. Rentsch, A.K.; Rufener, C.; Spadavecchia, C.; Stratmann, A.; Toscano, M.J. Effect of keel bone fractures on laying hen behaviour in a noncage housing system. In Proceedings of the XVth European Poultry Conference; Prukner-Radovčić, E., Medić, H., Eds.; World’s Poultry Science Journal: Dubrovnik, Croatia, 2018; p. 229.

41. Nasr, M.A.F.; Murrell, J.; Wilkins, L.J.; Nicol, C.J. The effect of keel fractures on egg production parameters, mobility and behaviour in individual laying hens. Anim. Welf. 2012, 21, 127-135. [CrossRef]

42. Stratmann, A.; Ringgenberg, N. Assessment of aviary systems for laying hens in Switzerland. In KTBL-Schrift 514. Aktuelle Arbeiten zur artgemäßen Tierhaltung 2018; Kuratorium für Technik und Bauwesen in der Landwirtschaft e.V. (KTBL): Darmstadt, Germany, 2018; pp. 137-147. ISBN 978-3-945088-60-9.

43. Janczak, A.M.; Riber, A.B. Review of rearing-related factors affecting the welfare of laying hens. Poult. Sci. 2015, 94, 1454-1469. [CrossRef] [PubMed]

44. Heerkens, J.L.T.; Delezie, E.; Rodenburg, T.B.; Kempen, I.; Zoons, J.; Ampe, B.; Tuyttens, F.A.M. Risk factors associated with keel bone and foot pad disorders in laying hens housed in aviary systems: Table 1. Poult. Sci. 2016, 95, 482-488. [CrossRef]

45. Stratmann, A.; Mühlemann, S.; Vögeli, S.; Ringgenberg, N. Frequency of falls in commercial aviary-housed laying hen flocks and the effects of dusk phase length. Appl. Anim. Behav. Sci. 2019, 216, 26-32. [CrossRef]

46. Moinard, C.; Rutherford, K.M.D.; Haskell, M.J.; McCorquodale, C.; Jones, R.B.; Green, P.R. Effects of obstructed take-off and landing perches on the flight accuracy of laying hens. Appl. Anim. Behav. Sci. 2005, 93, 81-95. [CrossRef]

47. Taylor, P.E.; Scott, G.B.; Rose, P. The ability of domestic hens to jump between horizontal perches: Effects of light intensity and perch colour. Appl. Anim. Behav. Sci. 2003, 83, 99-108. [CrossRef]

48. Heerkens, J.L.T.; Delezie, E.; Ampe, B.; Rodenburg, T.B.; Tuyttens, F.A.M. Ramps and hybrid effects on keel bone and foot pad disorders in modified aviaries for laying hens. Poult. Sci. 2016, 95, 2479-2488. [CrossRef]

49. MacLachlan, S.; Ali, A.; Stratmann, A.; Toscano, M.; Siegford, J. Prevalence of keel bone damage in laying hens can be influenced by using ramps in pullet rearing and laying hen aviaries. Poultry Sci. 2018.

(C) 2020 by the authors. Licensee MDPI, Basel, Switzerland. This article is an open access article distributed under the terms and conditions of the Creative Commons Attribution (CC BY) license (http://creativecommons.org/licenses/by/4.0/). 